\title{
Education and the changing face of medical professionalism: from priest to mountain guide?
}

Sean Hilton

\section{INTRODUCTION}

It is an honour to present the 40th William Pickles lecture of the Royal College of General Practitioners (RCGP). Past lecturers have included people I revere, people who have been my career heroes, and people who I count among my closest friends, and so I feel privileged to join the list. This lecture is expected to take an educational theme, although a few have focused on research in general practice. In reviewing the manuscripts of previous lectures, which has been a journey of great value to me, numerous themes and topics have appeared, some more frequently than others. They have ranged across the spectrum of medical education, invoked the practice of Pickles' time, or looked at the content of general practice.

Is it possible to say anything genuinely new or original about general practice education after 40 years? As I made my way through the years from 1968 onwards, a time corresponding exactly to my own career from aspiring medical student to the present, I was initially disappointed that all of what I thought might be original reflections and insights about education and general practice had been said by others before me (often several times). Gradually this disappointment was replaced by a reassurance about the ideals and values that this College stands for, that of enhancing patient care and maintaining the highest possible standards, and also of our commitment to education as the most important means to attain these.

So the content of this lecture is not so much new, as enduring. I will aim to place it in today's context, and to look to the future, but I would like briefly to review the past in order to set the context.

Pickles lecture titles have shown greater variation than their messages and themes - from the cryptic and snappy to the lengthy (Box 1). My title is lengthy, and rather opaque, and I need by the end to justify it. My subject is constancy and change (very close to Sir George Godber's 1985 title Change and continuity). ${ }^{4}$

\section{HOW LIFE HAS CHANGED FOR GENERAL PRACTICE}

While many Pickles lectures have been set in a context of changing times, or at a time of unprecedented challenge (and it is tempting to do so again), the reality

\author{
Box 1. Past Pickles lectures. \\ - The passing of the 'eight' train, 1968 \\ - Peter Piper's peck, $1976^{2}$ \\ -... But now what? Some unresolved problems of \\ training for general practice, $1990^{3}$
}

is that change is constant. I suspect it is only in retrospect that we see periods of relative calm. If we take big leaps backwards we can regard with bemusement the image of our GP predecessors in the middle of the last century carrying out tonsillectomies on kitchen tables; and then in near disbelief at the image of William Pickles' father John, as a GP in the late 19th century carrying out autopsies on his deceased patients in their own homes. ${ }^{5}$ It makes one wonder about the consent procedures involved in this, and contrast societal acceptance of such practice with the public reaction to Alder Hey. Medical practice has been changing rapidly and acceleratingly for well over 100 years, and perhaps it is the role of the doctor that has struggled to keep pace.

James le Fanu, in his book The Rise and Fall of Modern Medicine, ${ }^{6}$ describes 10 of the greatest postwar breakthroughs in medicine, including antibiotics, open heart surgery, and the discovery of Helicobacter. Against these triumphs, which have contributed greatly to unsurpassed health and longevity, he suggests four paradoxes for us to consider at the beginning of the 21st century:

- disillusioned doctors;

- worried well;

- soaring popularity of 'alternative' medicine; and

Sean Hilton, MD FRCGP, Vice-Principal, St George's, University of London and GP, Kingston upon Thames. This text is based on the William Pickles Lecture delivered on 18 May 2007.

Address for correspondence

Sean Hilton, St Georges, University of London, Cranmer Terrace, London SW17 0RE.

E-mail: shilton@sgul.ac.uk

Submitted: 17 September 2007; Editor's response: 21 November 2007; final acceptance: 15 January 2008. @British Journal of General Practice 2008; 58: 353-361. DOI: 10.3399/bjgp08X280128

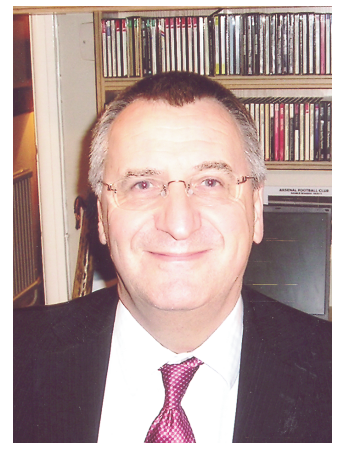


- spiralling costs of health care.

Without signing up to le Fanu's fierce attacks on social theory and the new genetics, we can surely accept that these paradoxes have come to the fore during the lifetime of the Pickles lecture.

Finally on this point, some of my early learning about acting responsibly as a doctor was predicated on this teaching by our mentors, that the authority of a doctor comes from three sources: moral, sapiential, and charismatic.

- Moral: evidenced by the undisputed altruism of medical practice.

- Sapiential: evidenced by our exclusive ownership of an esoteric body of knowledge that only the profession can pass on to the next generation.

- Charismatic: exemplified by the august consultant with a large retinue of accompanying staff and students.

All of these sources of 'authority' have changed substantially, I will not say that they have disappeared. If we regret this bitterly, we will be disaffected and disillusioned. If we recognise it, we will adapt, and move forward constructively. I will return to this point.

\section{DOES GENERAL PRACTICE HAVE A FUTURE?}

Notwithstanding the prospect of polyclinics, or of independent general practices appearing in supermarkets, let me resist the temptation to label 2007 as a watershed, and suggest that recent developments have indeed brought general practice to a crossroads, but only the latest of many (Box 2).

These developments have not all occurred de novo in 2007, but together they pose a set of threats and challenges to a model of GP care that relies on generalist medical care provided by a compact team to a registered list of patients.

\section{Continuity of care}

From the moment we relinquished 24-hour, 365 daysa-year responsibility for care, there would inevitably be

\section{Box 2. General practice at its 2007} crossroads.

- Loss of 24-hours cover, threats to continuity

- Dual registration

- Increasing specialisation

- Demand management

- Commissioning

- Private providers

- Contractual straitjacketing

Partnership commitments changes in the ways in which we are viewed by our patients, and in the public perception of what general practice is. Paul Freeling said in 1978:

'The special functions of the GP stem from the context in which he practises: their permanence rests on the degree to which that context is likely to persist."

The degree of continuity that William Pickles was able to provide for his communities in Wensleydale, and which formed the basis for his research, has not proved to be sustainable for modern, diverse, mobile, more demanding populations, and the entry of other providers of our core functions is indeed a threat to the special functions of the GP.

Loss of continuity is further complicated by diversification of the workforce with new practitioner roles, plus the acceleration of what we have referred to for years as the secondary to primary care shift. There was a time when the terms general practice and primary medical care were almost synonymous. With the exception of some preventive work, virtually all primary medical care took place under the aegis of general practice. Today, the distinction between primary and secondary care is less distinct, and possibly unhelpful. We wrestle with terminologies such as intermediate care and local care, and worry about the impact of GPs with special interests on good generalist care for complex cases.

Is this so new? Issues of continuity have been with us since single-handed practice moved towards group practices; since uniprofessional practices started becoming multidisciplinary teams.

\section{The public health function}

While for many years we were adjusted to our implicit and unregulated role as gatekeepers to secondary care, the evolution to today's 'personal public health' practice, through fundholding, to primary care groups, to practice-based commissioning has brought with it a new set of challenges, particularly when it is aligned more and more closely with practice income, via the Quality and Outcomes Framework and practice-based commissioning.

Neither is this is an entirely new challenge. Long before the 1990 contract, Parry was reminding us in the 1977 lecture of William Pickles' dual role as medical officer of health for the Aysgarth Rural Health District, that:

'All doctors have a managerial role in the sense that the decisions they take affect the people with whom they work, and the use of resources. With the growth of professional interdependence and increasing economic constraint such managerial 
roles need to be recognised. ${ }^{8}$

\section{Partnerships}

Partnerships, for 40 years the bedrock of continuity of care for practice populations, are also changing rapidly, and beginning to be replaced by alternative provider models. Young doctors entering practice are, in some cases, less likely or able to want to make longterm commitments to the demands of partnership, and some are more likely to want to build a portfolio career.

So, once again, there is a huge agenda for change, and a range of challenges for general practice to address. Some of them are undoubtedly threats. The college's immediate past president Roger Neighbour was asked in a recent interview whether general practice could survive, and gave an unequivocal answer: 'Adapt or face extinction' (R Neighbour, personal communication, 2006).

The 1985 RCGP initiative What sort of doctor? laid down the gauntlet to GPs to review their practice and the standards they were achieving. ${ }^{9}$ Given the major changes occurring in general practice, it seems reasonable to pose that question again. What sort of doctor do we need for general practice for the future? There are two subsidiaries: who should answer that question and how can we enable that sort of doctor to emerge?

The latter I will address later in the lecture, but as for the question 'who should answer?', in the days of unopposed self-regulation of the profession, there could have been only one response: the profession would define it and judge it. Yet even 40 years ago Pat Byrne made this statement:

'We could, with advantage, be seen to be more humble. The patient is the focal point for the medical care team. He must be part of the team which constructs and evaluates experiments in medical care."

Finding the answer to the question is no longer solely our preserve. 'Patient-centred professionalism' is an international initiative by the Picker Institute Europe. ${ }^{10}$ In partnership with the profession and healthcare organisations, they are seeking to improve health care by examining the public's experiences and expectations of doctors and medical care. Their aim is to help the medical profession to shape its values, roles, and responsibilities so that all doctors give care that is truly patient centred.

Patient-centred care as a concept causes us no problems. It was one of Hayden's themes in 2002:

'Patient centredness is not the sole province of GPs. Patients and the NHS need doctors throughout primary, secondary and tertiary care who are able to understand the patients' perspective and share management plans."

And yet there is an uncomfortable edge to it. Because it now pervades the dialectic about health care in a way it didn't 10 years ago, there is an element of the pejorative in its recency, and we are suspicious of it. We bridle a bit, and protest, 'but we've always been patient centred', and yes, so we have to an extent, but there is more to it than that. Patient centredness is an important signal to our professionalism. Godber, in 1985, highlighted the movement for patient participation, and also noted that the social basis of medicine was evolving just as fast as the scientific content, so that:

\section{'... the whole of medicine in the future will depend on a different relationship with people from that which Will Pickles had in Wensleydale 50 years ago. ${ }^{4}$}

Nevertheless, there is a tension when, as hardpressed professionals, we are challenged, sometimes hectored, to be more patient centred. But a creative tension may be helpful to us in our need to adapt and survive.

Dee Hock is an American business guru, a man who single-handedly transformed the anarchy of the American credit card industry of the 1960s to the trillion dollar success that is the Visa organisation. ${ }^{12}$ Such a person might seem an unlikely source of advice for NHS general practice. Yet he embraces humanism and complexity theory in declaring that 'Substance is enduring, form is ephemeral', ${ }^{12}$ and that success follows those able to distinguish between the two, and to preserve substance of the past by adapting it to forms of the future.

$\mathrm{He}$ coined the term 'chaordic organisations' for those complex adaptive systems that operate in the zone between chaos and order. ${ }^{13}$ This seems to me to be a near-perfect term for our beloved NHS, with its puzzling blend of compassion and apparent indifference, of bureaucracy and anarchy, of technological successes and disasters, and of micromanagement while preaching empowerment.

Is there a permanence that defines 'what sort of doctor' we need? If so, how will that doctor deliver the entitlement of general practice to be at the core of the NHS, howsoever it changes?

The quote that has most inspired my thinking and teaching, about medicine broadly, but general practice in particular, was by a great paediatrician named Sir James Spence, rather than a GP:

'The essential unit of medical practice is the occasion when, in the intimacy of the consulting 
room, a person who is ill, or believes himself to be ill, seeks the advice of a doctor whom he trusts. This is a consultation, and all else in medicine derives from it'. ${ }^{14}$

It is intriguing, therefore, to learn from John Walker's 1983 Pickles lecture about the friendship between Pickles and Spence. Walker speculated that when producing this classical definition of the consultation Spence may well have had a mental picture of Will Pickles at work in a country cottage. ${ }^{15}$

Spence's eloquent statement conveys the substance of Hock's thesis, and a shift to patientcentred professionalism will clothe it in a form that is fit for the foreseeable future.

To this point, I have considered how life has changed for general practice, and reviewed some of the challenges and threats that can make us confident that change will be continuous. The consultation, and in this I incorporate the generalist approach to diagnosis, is the core 'substance' of our discipline. The next section focuses on medical professionalism: its definition, and how it must change in response to societal change.

\section{MEDICAL PROFESSIONALISM}

In recent years professionalism has been one of the most prominent topics in the medical education literature, its definition, its attainment, its assessment, all fraught with difficulties. Twenty years ago there was very little presence of the topic in debate or in the literature. It was there of course, tacit, implicit, role-modelled for all of us. Medical professionalism was the predominant model within the fledgling NHS - omniscient, paternalistic, but by no means all bad. A mid-20th century definition of the professions would include:

- a body of specialist knowledge and skills;

- a commitment to high standards of service;

- varying degrees of self-regulation and autonomy;

- high standards of ethical behaviour; and

- control of entry, education, and training for the profession.

This model was predominant for some time; indeed it was strengthened by the great technical and scientific advances of the 1960s and 1970s. But these very advances brought new challenges. If it was once thought that the early NHS was relatively ineffective, but at least was relatively inexpensive and safe, then today it is effective but expensive and dangerous.

The formerly implicit (and predominant) model of medical professionalism now has to coexist with other models that influence the running of our health service: those of regulation through management and increased accountability, and of consumerism. Today's medical professionalism has to be made explicit, redefined, and adapted to respond to these changes.

The words 'professional' and 'professionalism' have many different connotations and interpretations: from simply being paid for what one does, to efficient competence, to the implied cynicism of the sportsman's 'professional foul'. I argue for a broad view of the term 'medical professionalism', such that it encompasses all that we do, and makes the difference between a doctor and a good doctor.

Prominent organisations have led efforts to redefine medical professionalism in recent years. In the mid1990s, the General Medical Council published the first edition of Good Medical Practice and a code of practice listed as 'Duties of a doctor'. ${ }^{16}$ The Canadian colleges defined the future specialist physician for the turn of the millennium, arguing that the specialist of the future would need to fulfil seven separate roles; those of medical expert, communicator, collaborator, manager, health advocate, scholar, and professional. ${ }^{17}$ It is noteworthy that they view the role of professional as separate from others including medical expert, communicator, and collaborator.

The combined forces of the American Board of Internal Medicine, the American College of Physicians, and the European Federation of Internal Medicine first published the Physicians' Charter in 2002. This states that the medical professionalism requirement for the new millennium rest on three fundamental principles, those of the primacy of patient welfare, of patient autonomy, and of social justice, and also on a set of professional responsibilities. ${ }^{18}$

Cruess and Cruess have written extensively about the changing medical professionalism. ${ }^{19-22}$ They distinguish between the ancient and unchanging role of the physician as healer and the more recently acquired role as a professional. The latter exists as an implicit social contract between the profession and society. They argue that it is this that has been damaged over the last 40 to 50 years, and that it must be renegotiated and stated explicitly. Kuczewski has offered a concise definition of professionalism as 'The norms of the relationships in which physicians engage in the care of patients'. ${ }^{23}$ This recognises changing societal norms including, but not exclusively, those between doctor and patient. Cosgrove has argued that professionalism is a state to be attained, not simply a trait that is collected with the degree certificate at qualification. ${ }^{24}$ Having been attained it must be maintained, or it may be lost. The Royal College of Physicians' working party on medical professionalism published a report in 2005 that proposed this definition:

'Medical professionalism signifies a set of values, behaviours and relationships that underpin the trust the public has in doctors'. ${ }^{25}$ 
This underlines the centrality of trust as a requisite for society and for professions, as so brilliantly argued by Dame Onora O'Neil in her 2002 Reith lectures. ${ }^{26}$ But this is trust that is earned, not the 'blind' trust (in O'Neil's terms) that, at least in part, led to the events of Bristol and of Shipman. There is one central feature of professionalism (missing from a number of descriptions) to consider before proposing a broad definition of this term. Going back more than 2000 years to the earliest times of the physician, Aristotle did not use the term 'professionalism' but he wrote about it. ${ }^{27}$ In education, we are very familiar with knowledge, skills, and attitudes as components of our learning outcomes, but this is rather different.

\section{In Aristotle's terms:}

- 'episteme' is the knowledge base that underpins our professionalism; and;

- 'techne' the necessary clinical communications and procedural skills; but

- 'phronesis' represents professional judgement.

Literally, phronesis means practical wisdom or 'prudence'. As Peter Toon argues in his College monograph on the virtuous practitioner, 'the word prudence in English has a puritan and mean spirited feel to it, with overtones of avoiding trouble and keeping one's hands clean'. ${ }^{28}$ This is not the excellence of phronesis of which Aristotle wrote, as the capacity to link technical and moral judgement to achieve right ends, as set out in a description of phronesis by Pellegrino:

'The capacity to select the right means and the right balance between means and good ends. ${ }^{29}$

Many others have written about this quality, or something closely related (Box 3 ).

Phronesis is the quality that the good professional needs when the algorithm runs out, or when there is a conflict between the guidelines and the reality of the situation, or conflicts of interest between different patients or team members. It justifies the trust in the doctor to make the best decision in the interests of the patient that is at the heart of Spence's definition. If that trust is eroded too far, either by our own actions or those of society, no amount of regulation or legislation will be able to compensate for it. The hallmark of professionalism is phronesis, and it needs to be applied broadly to all that we do as professionals. A model for this, described by Hilton and Slotnick, is of six domains: ${ }^{35}$

- ethical practice;

- reflection/self-awareness;

- responsibility for actions;

\section{Box 3. Variants on 'phronesis'}

- Reflective judgement: King and Kitchener ${ }^{30}$

- Reflection-in-action: Schon ${ }^{31}$

- Personal knowledge: Polanyi ${ }^{32}$

Professional judgement: Coles and Fish ${ }^{33}$

Capability: Fraser and Greenhalgh ${ }^{34}$

- respect for patients;

- working with others; and

- social responsibility.

The first three relate to our intrinsic characteristics and the second three to the ways in which we interact with others. ${ }^{35}$ All have been addressed in previous William Pickles lectures, and each is described briefly with reference to these.

\section{Ethical practice}

'... efforts to improve performance must come from a desire for self-improvement, a desire based on an essentially ethical insight'. ${ }^{36}$

Our core values of ethical practice should inform what we do not only in consultation but in all interactions. Michael Boland's lecture title was 'My brother's keeper'. ${ }^{36}$

\section{Reflection/self-awareness}

I believe this to be nowhere better defined than by Ronald Epstein in his term 'mindfulness', ${ }^{37}$ but this from James Knox in 1976 is close:

'... that mental state of readiness to respond, organised through past experience'.2

\section{Responsibility for actions}

This domain incorporates taking responsibility for decisions, for lifelong learning, and continuing clinical competence. George Swift's 1973 lecture 'Education for responsibility' had a theme close to mine today:

'Success or failure, happiness or unhappiness, will depend on his conscience, his ethics, and his ability to criticise and understand himself', ${ }^{38}$

\section{Respect for patients}

David Pendleton took professional development as his theme in 1995:

'Yet the future will require the same values of medical care as in the past - the value of health and healing, of expertise and rigour, and of respect and care for individuals'. ${ }^{39}$ 
Figure 1. Proto-professionalism - a model to describe influences on development of professionalism from medical student to mature professional (from Hilton and Slotnick 2005 reproduced with permission from Wiley-Blackwell Publishing). ${ }^{35}$

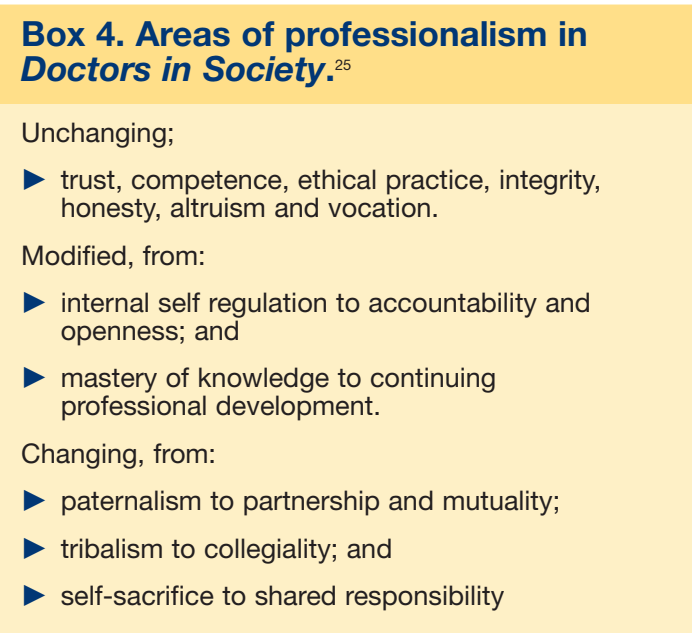

\section{Working with others}

Working with others includes teamwork, but is broader to include all those we work with. John Horder has done more than anyone to promote this in primary care through interprofessional learning and mutual respect:

'The essence of success is in democratic discussion, in continuing self-criticism, and in auditing the work of the practice'. ${ }^{40}$

\section{Social responsibility}

We hold social responsibility beyond our immediate teams and workplace to broader systems and communities, and to retain involvement with social change.

'Yet medicine changes, society changes, and

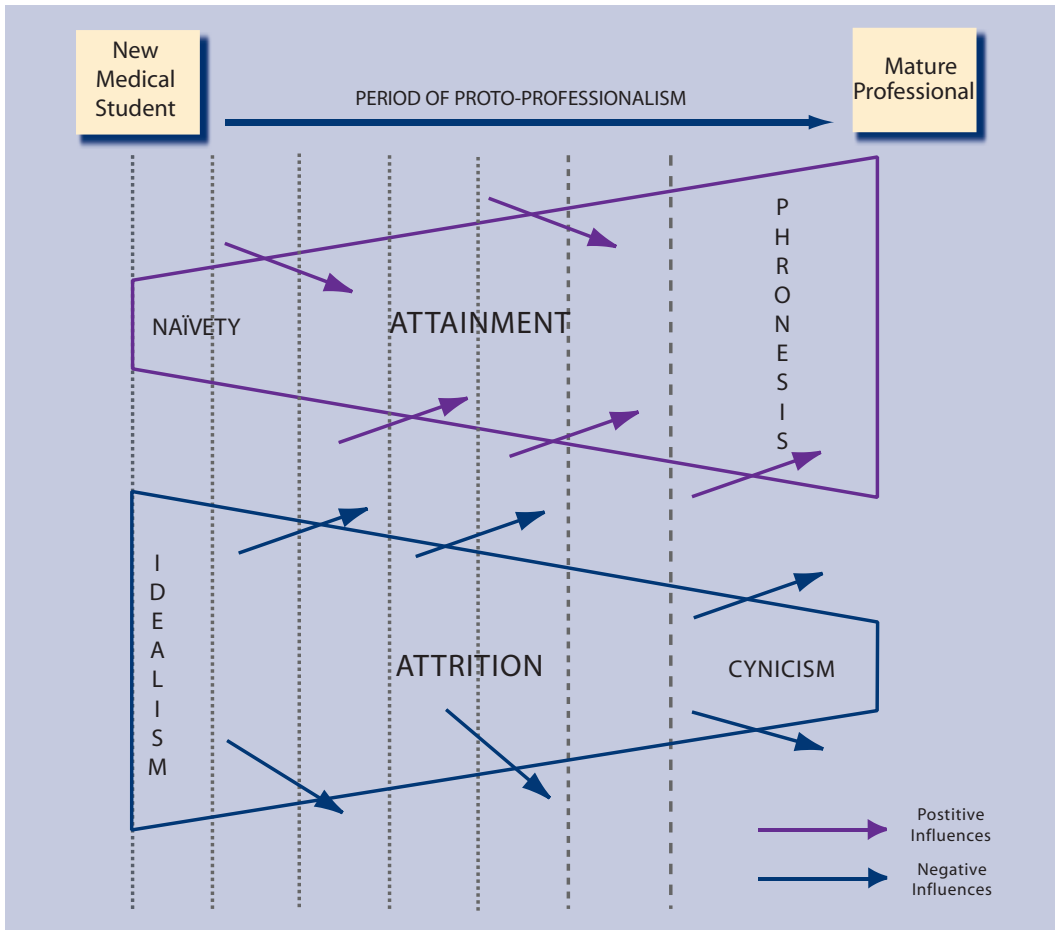

health services change, so doctors must be able to change, and that change must be growth'. ${ }^{39}$

In response to Neighbour's challenge to adapt or face extinction, I believe that in whatever ways we adapt, we must preserve the professionalism that integrates knowledge and competencies in ways that earn the trust and confidence of our patients. The Royal College of Physicians' report Doctors in Society describes areas of unchanging, modified and changing professionalism (Box 4). ${ }^{25}$

\section{ROLE OF EDUCATION}

How is professionalism acquired? Hilton and Slotnick have argued that professionalism, or at least its defining feature of phronesis, takes a long time to acquire. ${ }^{35}$ It covers at least undergraduate and postgraduate education and probably some time beyond. We have called this phase protoprofessionalism, the transition from the naivety of the new medical student to the phronesis of the mature professional.

If the term has merit, it is to underline the importance of 'metacognition' (of learning and reflection) in addition to the cognitive and practical aspects of our profession. As Aldous Huxley once said:

'Experience is not what happens to you, it is what you do with what happens to you. ${ }^{341}$

This is not to imply that we should not expect competence and professional behaviour from our students and trainees, rather it is to emphasise that education has a major role to play in the acquisition of full professionalism, as well as in knowledge and competence.

There are numerous positive influences on the attainment of professionalism, but education is the most important, and its influence should be there from day one (Figure 1).

But also, there is a countercurrent to the positive influences on personal growth in the attrition model. In this, the youthful energy and idealism of the new medical student may be eroded gradually to the point of burnout and cynicism. At worst, medical education may contribute to this through inappropriate methods, perverse incentives, or negative role models. At best it should act as a counter to those influences that are, frankly, antiprofessional.

In summary, the role of education is to maximise attainment of professionalism and its maintenance, and to minimise decay. The features that hold sway in traditional undergraduate curriculum and postgraduate training (Box 5) are essential, but my belief is that our education will be optimal only when we strike the right balance for each of them. 
Even the great William Osler argued for balance of science and humanities, although as Buckley pointed out in 1994, this was because of the dearth of science in medical education of the time. ${ }^{42}$ It was Schon who argued that technical rationality has its limitations in the 'swampy lowlands' of the complex problems encountered by professionals. ${ }^{31}$ Heath and Willis have developed this theme of balance in their inspired 'squirrels' analogy with 'red' and 'grey' professionalism. ${ }^{43}$

Traditionally, there have been three distinct phases to the curriculum for our medical careers; undergraduate, postgraduate, and continuing medical education. We are now much closer to a continuum, and the education agenda is rightly common to all, a template based on Good Medical Practice. ${ }^{16}$

In 2001, Hilton and Smail proposed a lifelong curriculum for general practice, arguing that such an approach was not only desirable, but also more feasible that at any time previously. ${ }^{44}$ The following were suggested as components of that curriculum:

- long-term nature of diseases;

- long-term nature of doctor-patient relationship;

- patient involvement and motivation;

- multiprofessional teamwork; and

- informatics and technology in health.

In the years since, opportunities have increased further. Today, general practice and primary care is prominent right through undergraduate education through to the commencement of specialty training, with around half the practices in the country contributing to GP teaching for undergraduates.

In the curriculum at my own medical school we have four themes that run through the course: basic and clinical sciences, patient and doctor, community and population health, and personal and professional development. These themes map on to a career-long curriculum for professionalism. Similarly, for the new curriculum for general practice training, and for the emerging framework for continuing professional development from the College's Professional Development Board we can propose an agenda that maps onto the acquisition and maintenance of professionalism (Figure 2).

A final point with respect to education and the lifelong curriculum arises from the 2005 Royal College of Physicians report on medical professionalism. ${ }^{27}$ The report made 17 recommendations within six themes, but 11 of them come under the headings of leadership and education (Box 6).

They are being addressed in a number of ways, not least in the College's own leadership unit. A joint project between the Academy of Medical Royal

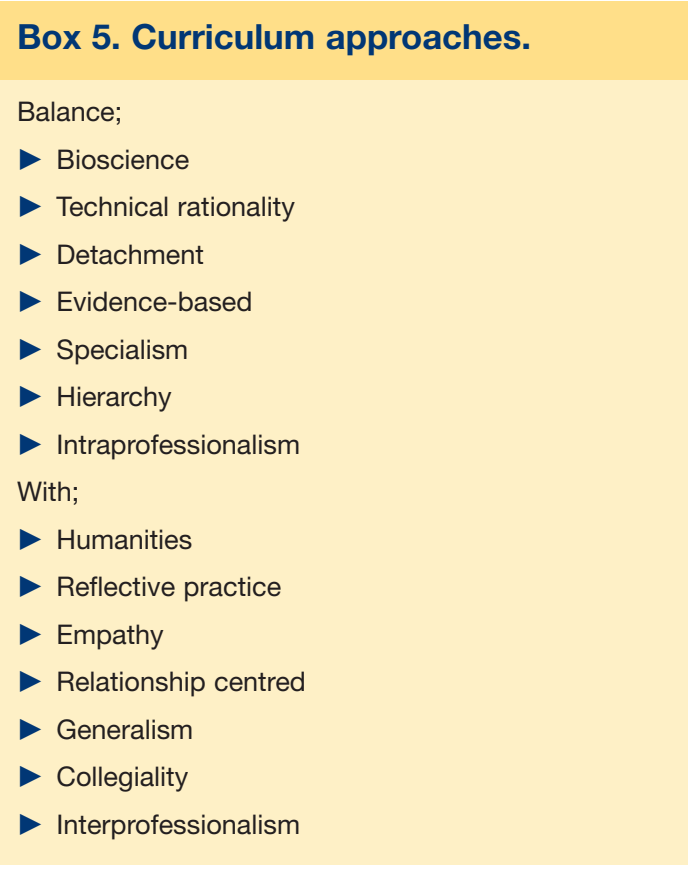

Colleges and the NHS Institution for Innovation and Improvement is developing a competency framework for leadership and management education from undergraduate through to 5 years post-Certificate of Completion of Training (CCT). ${ }^{45}$

The long-term aim is to support the development of leadership and management aspects of professionalism in this model, where the more advanced aspects of leadership management and strategy are fostered by a lifelong curriculum.

Figure 2. Domains of professionalism for a lifelong curriculum.

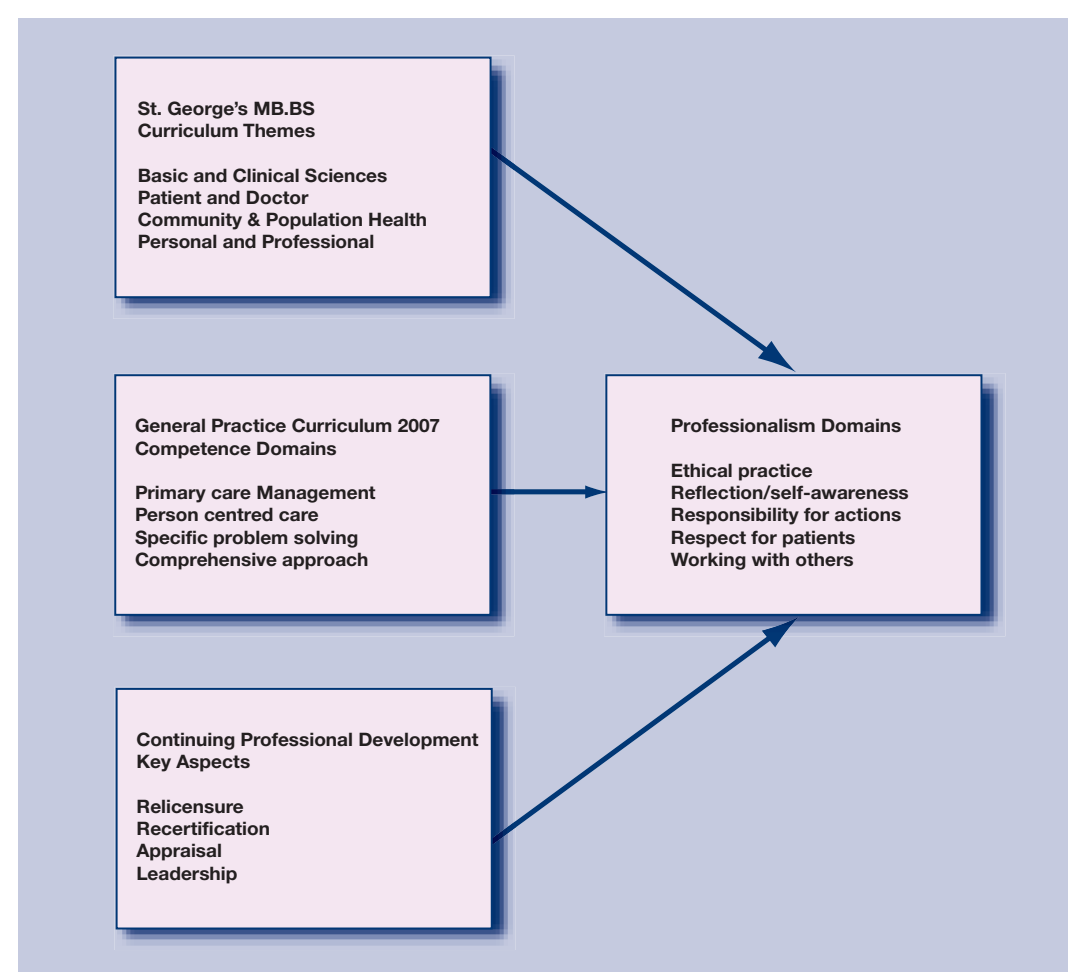




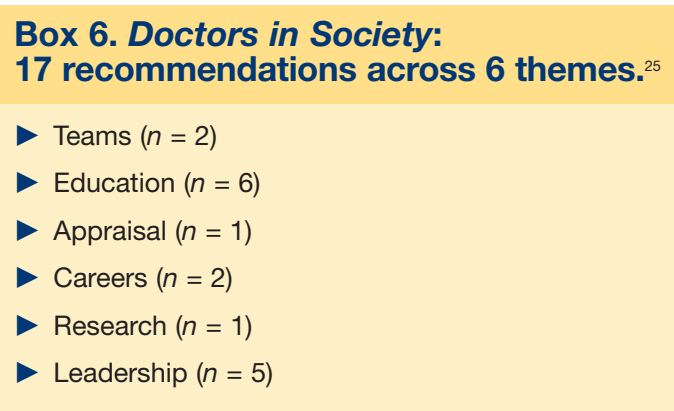

Why is this so important? I believe that it is this aspect of our professionalism that most urgently needs to be rethought and implemented. If we consider recent glaring examples of problems within the NHS, it is tempting to attribute these solely to political interference and bureaucratic incompetence. Indeed those do play a major part, but problems are also a consequence of longer-term disengagement and disillusionment of medical leadership. I am not suggesting that the profession is to blame for this, but it is part of the problem, and must be part of the solution. By better engagement of medical leadership in all parts of the system and at all stages, we can maximise the domain of social responsibility with our professionalism.

\section{FROM PRIEST TO MOUNTAIN GUIDE?}

Hafferty, the American sociologist in opening his book on the professionalisation of medical students writes:

'Medicine like religion touches on the core of our existence. We turn to medicine as a talisman, to ward off the uncertainties that compose our being'. ${ }^{46}$

In the first Pickles Lecture in 1968, Byrne quoted Cardinal Heenan, Roman Catholic leader in the UK who said, when addressing a medical audience in 1967:

\footnotetext{
'You are the new clergy, you - and especially the general practitioners amongst you are the modern priests'. 1
}

Forty years on that analogy seems much less appropriate. Depending on your viewpoint, and to some extent where you work, we have become a secular society or a multifaith society. Our relationship with patients is evolving. We no longer have moral, sapiential, and charismatic authority as of right.

In his book The Courage to Teach, Palmer analyses good teaching from the basic premise that it can only come from the identity and integrity of the teacher. ${ }^{47}$ In many ways the book might also be titled The courage to consult:
'When we are willing to abandon our selfprotective autonomy and make ourselves as dependent on our students (patients) as they are on us, we move closer to the interdependence that the community of truth requires'.

Now this is heady stuff, and as emphasised in the previous section I believe we must strike a judicious balance between science and humanities, independence and interdependence and so on, in seeking that doctor-patient partnership in our evolving relationship with patients.

In one passage of his book, Palmer relates a method he uses to generate discussion in workshops. He invites participants to fill in the blank in the following statement:

\section{'When I am teaching at my best I am like a ...' ${ }^{47}$}

His own metaphor is that of a sheepdog, maintaining a space, protecting the sheep, guarding the boundaries, and moving them on when ready. If a priest is no longer an appropriate analogy for our relationship with patients (and for me it is not), then what is?

Independently of Palmer's book I had already considered the mountain guide metaphor, but it does seem to me that when I am consulting well, I am like a mountain guide. Consider these thoughts from Lou Whittaker, who had a career as a mountain guide in the Rockies, but has also scaled many of the world's greatest peaks, including Everest. ${ }^{48}$

'A good guide has to be patient and not too ego-driven.'

'In the early days we didn't teach self-arrest, because we actually thought the less the client knows the better. We felt it was too much for them to think about.'

'In my mind there are no kings of the mountain. A mountain decides who will climb it and who will not. Sometimes you feel like a king ... Most of the time you feel pretty humble. The higher you get, the more insignificant you feel. That's not a bad feeling. ${ }^{48}$

It does seem to me we all face personal mountains, and maintaining health and wellbeing is one of them. If I needed a mountain guide, as a professional I would expect him/her to be a highly competent climber, to be interested in me as a climber and in my goals, to communicate well and advise me expertly, to judge difficult circumstances in ways I could trust, and to be prepared to go out on a limb for me. Should our patients expect anything less from us as their doctors? 


\section{CONCLUSION}

In 40 years of William Pickles lectures, general practice has changed enormously, and we appear almost routinely to have been at times of unprecedented change. This year is no exception, with major changes and challenges approaching general practice. We face financial uncertainty, shared services, merging practices, new providers. I have attempted to identify issues that have remained constant by reference to past lecturers.

I have argued that with sufficient flexibility we can, and must, adapt successfully to deal with the future. To paraphrase Hock, this year's NHS reorganisation is an ephemeral form, but our professionalism must have permanence, and our education must foster it." Current structures hand us the opportunity for a lifelong general practice curriculum of professionalism that incorporates clinical competence, good medical practice, leadership, and management.

Byrne drew an analogy with priests in $1968,{ }^{1}$ and I have suggested a mountain guide in 2007. Whatever the analogy, our relationship with patients is paramount. We must ensure that it both endures through and adapts effectively to changing societal norms. Several previous Pickles lecturers have alluded to hills and mountains. If you make the pilgrimage to Aysgarth, to visit William Pickles' home and practice, you will find a plaque to his memory in the centre of the village. The plaque bears a simple legend, and at the bottom is the College motto 'Cum Scientia Caritas' which just about encapsulates all I have tried to say in this lecture. We will do well to hold on to that motto in the coming years.

\section{Competing interests}

The author has stated that there are none.

\section{Discuss this article}

Contribute and read comments about this article on the Discussion Forum: http://www.rcgp.org.uk/bjgp-discuss

\section{REFERENCES}

1. Byrne PS. The passing of the 'eight' train. J R Coll Gen Pract 1968; 15(6): 409-427.

2. Knox JD. William pickles lecture 1976: Peter Piper's peck. Br J Gen Pract 1976; 26(168): 476-484.

3. Styles WMcN. But now what? Some unresolved problems of training for general practice. Br J Gen Pract 1990; 40(336): 270-277.

4. Godber G. Change and continuity. J R Coll Gen Pract 1985; 35(276): $320-325$

5. Pemberton J. Will Pickles of Wensleydale. Exeter: Royal College of General Practitioners, 1984

6. Le Fanu J. The rise and fall of modern medicine. London: Abacus, 1999 .

7. Freeling P. Those who can. J R Coll Gen Pract 1978; 28(191): 329-340.

8. Parry KM. Community practice. J R Coll Gen Pract 1977; 27(179): $327-333$

9. Royal College of General Practitioners. What sort of doctor? Report from general practice 23. London: RCGP, 1985.

10. Picker Institute Europe. Patient-centred professionalism. http://www.pickereurope.org/page.php?id=9 (accessed 25 Feb) 2008).

11. Hayden J. Young ambition's ladder. Br J Gen Pract 2003; 53(487): 143-148.

12. Hock DW. One from many: Visa and the rise of chaordic organization. San Francisco, CA: Berrett-Koehler Publishers Inc, 2005.

13. Hock DW. Birth of the chaordic age. San Francisco, CA: Berrett-Koehler Publishers Inc, 1999.
14. Spence, $J$ The need for understanding the individual as a part of the training and functions of doctors and nurses. (Speech delivered at a conferen a . In: The purpose and practice of medicine: selections from the writings of Sir James Spence. Oxford: Oxford University Press; 1960: 273-274.

15. Walker JH. Quantity, quality and controversy. J R Coll Gen Pract 1983; 33(254): 545-556

16. General Medical Council. Good medical practice. London: GMC, 2002.

17. CanMEDS 2000 Project Group. Skills for the new millennium: report of the societal needs working group. University of Toronto, Canada: CanMeds, 2000. http://www.deptmedicine.utoronto.ca/CanMEDS.htm (accessed 21 Jan 2008).

18. Medical Professionalism Project. Medical professionalism in the new millennium: a physicians' charter. Lancet 2002; 359: 520-522.

19. Cruess R, Cruess S, Johnston SE. Renewing professionalism: an opportunity for medicine. Acad Med 1999; 74(8): 878-884.

20. Cruess R, Cruess S, Johnston SE. Professionalism and medicines' social contract. J Bone Joint Surg 2000; 82(A8): 1189-1194.

21. Cruess RL, Cruess SR. Teaching medicine as a profession in the service of healing. Acad Med 1997; 72(11): 941-952.

22. Cruess S, Cruess R. Professionalism must be taught. BMJ 1997; 315(7123): 1674-1677.

23. Kuczewski M. Developing competency in professionalism: the potential and the pitfalls. ACGME Bulletin 2001; October: 3-6.

24. Cosgrove E (ed.). Professionalism: a state not a trait. Group on Educational Affairs. Washington, DC: AAMC, 2001.

25. Royal College of Physicians Working Party. Doctors in society. Medical professionalism in a changing world. London: RCP, 2005.

26. O'Neil O. A question of trust. Reith Lectures 2002. http://www.bbc.co.uk/radio4/reith2002/ (accessed 21 Jan 2008).

27. The ethics of Aristotle, the Nicomachean ethics, revised translation. (Thompson JAK trans.) London: Penguin, 1976.

28. Toon P. Towards a philosophy of general practice: a study of the virtuou practitioner. Occasional Paper 78. London: Royal College of General Practitioners, 1999.

29. Pellegrino ED. Professionalism, profession and the virtues of the good physician. Mt Sinai J Med 2002; 69(6): 378-384.

30. King PM, Kitchener KS. Developing reflective judgement. San Francisco, CA: Jossey-Bass, 1994

31. Schon D. The reflective practitioner. New York, NY: Basic Books, 1983

32. Polanyi M. Personal knowledge: towards a post-critical philosophy. New York, NY: Harper Torchbooks, 1962, 174-184.

33. Coles C, Fish D. Developing professional judgement in health care: learning through the critical appreciation of practice. Oxford: Butterworth Heinemann, 1998.

34. Fraser SW, Greenhalgh T. Coping with complexity: educating for capability. BMJ 2001; 323(7316): 799-803.

35. Hilton S, Slotnick HB. Proto-professionalism: how professionalisation occurs across the continuum of medical education. Med Educ 2005; 39(1): $58-65$.

36. Boland M. My brother's keeper. Br J Gen Pract 1991; 41(348): 295-301.

37. Epstein RM. Mindful practice. JAMA 1999; 282(9): 833-839.

38. Swift G. William Pickles Lecture 1973. Education for responsibility. J $R$ Coll Gen Pract 1973; 23(131):389-399.

39. Pendleton D. Professional development in general practice; problems puzzles and paradigms. Br J Gen Pract 1995; 45(396): 377-381

40. Horder J. Education after the Royal Commissions. J R Coll Gen Pract 1969; 18(84): 9-21.

41. Huxley A. Visionary experience. In: White J (ed.). The highest state of consciousness. New York, NY: Archer, 1972.

42. Buckley EG. From Cullen to Calman. Medical education enlightenment to post-modernism. Br J Gen Pract 1994; 44(384): 326-330.

43. Willis J. The challenge to professionalism. Tom Stewart Memorial Lecture 2006. London: Royal College of General Practitioners, 2007.

44. Hilton S, Smail S. A lifelong curriculum for general practice? Education in general practice. Educ Gen Pract 2001; 12: 1-10.

45. NHS Institute for Innovation and Improvement. Enhancing engagement in medical leadership. Coventry: NHS, 2007. http://www.institute.nhs.uk/medicalleadership (accessed 21 Jan 2008)

46. Hafferty FW. Into the valley: death and the socialization of medical students. New Haven, CN: Yale University Press, 1991.

47. Palmer Parker J. The courage to teach: exploring the inner landscape of teacher's life. San Francisco, CA: Jossey-Blass, 1998.

48. Whittaker L, Gabbard A. Memoirs of a mountain guide. Seattle, WA Mountaineers Books, 1994. 